\title{
Models for Setting up Medical Information Services in Namibia
}

\section{David Matsveru}

Faculty of Social Science and Humanities, University of Fort Hare, Alice, Republic of South Africa

Email:dmatsveru@gmail.com

How to cite this paper: Matsveru, D. (2021) Models for Setting up Medical Information Services in Namibia. Open Access Library Journal, 8: e7730.

https://doi.org/10.4236/oalib.1107730

Received: July 4, 2021

Accepted: September 23, 2021

Published: September 26, 2021

Copyright (c) 2021 by author(s) and Open Access Library Inc.

This work is licensed under the Creative Commons Attribution International License (CC BY 4.0).

http://creativecommons.org/licenses/by/4.0/

\begin{abstract}
This paper proposes conceptual models of information seeking for medical doctors. The models are based on a study entitled "Information Needs and Information-Seeking Behavior of Practicing Medical Doctors at Katutura and Windhoek Central State Hospitals in Namibia" conducted between 2015 and 2018. Using a mixed-methods research approach, the study aimed to establish the information required by practicing medical doctors to carry out their work, how they seek information, the information sources and resources they use, and the factors that affect them as they do so. The proposed models are based on the premise that information service providers need to analyze the medical doctors' contexts, motivating factors, prevailing circumstances, information-seeking behaviors and information use.
\end{abstract}

\section{Subject Areas}

Library, Intelligence and Philology

\section{Keywords}

Information Needs, Information-Seeking Behavior, Model, Medical Information

\section{Introduction}

Using Wilson's 1996 model of information-seeking behavior as the theoretical framework [1], this study was conducted to establish the information needs and information-seeking behavior of practicing medical doctors at the Katutura and Windhoek Central State hospitals in Namibia. After independence in 1990, the Government of Namibia adopted the primary health care approach with the aim of achieving health for all Namibians by 2030 . To achieve this, the referral system was introduced. The Ministry of Health and Social Services (MOHSS) as the 
principal provider of health care services is responsible for ensuring that the health care system is managed correctly.

Medical doctors working in state hospitals are a central part of the Namibian health delivery system. Their information needs and information-seeking behavior are critical in improving the current state of health information services provision. Medical doctors are trained at different medical schools and serve in hospitals that vary socially, economically, and politically, thus, their information-seeking behavior could be affected by their different contexts [2]. A wellinformed medical doctor will save time with patients as well as deliver better quality service. Therefore, it is necessary to know how well equipped and informed doctors are to deal with different medical situations in order to provide better information services to this category of information users as well as contribute meaningful empirical data to the Hospital Management Information System.

Different researchers have given conflicting information as far as the information-seeking behavior of practicing medical doctors is concerned. Some studies have pointed out that health personnel are enthusiastic about using the Internet because it reduces isolation and facilitate international cooperation [3] [4]. However, another scholar argues that health personnel perceive computers as irrelevant to their profession [5]. To this effect, some scholars reiterate that this is why health care professionals continue to face a daunting challenge when it comes to searching for information and remain uninformed about the advances in their discipline [6].

Although practicing medical doctors in Namibia may be aware of many different diseases that they encounter during their clinical practices, newer forms and strains of diseases, strange symptoms and unknown ailments, among other factors, can result in medical doctors engaging in information-seeking activities. The understanding of users' information needs and the way information is disseminated through an organization is needed in creating a fruitful system and providing quality services. Therefore, studying the needs of information and information-seeking behavior of doctors in different settings is a key to find out doctors' perceptions of their need for information for good medical decision-making and developing a successful information provision system that would help them in their practice. In this paper the researcher attempts to answer the question, "How may health information services for Namibian practicing medical doctors be improved?" This is done by proposing conceptual models of information seeking for medical doctors at Katutura and Windhoek Central state hospitals.

\section{Background}

After independence, the Government of Namibia adopted the primary health care approach with the aim of achieving health for all Namibians by 2030. To achieve this, the referral system was introduced. The MOHSS as the principal 
provider of health care services is responsible for ensuring that the health care system is managed correctly. The health care system is divided into three main levels of health care delivery, namely, primary, secondary, and tertiary. In a referral system, patients are referred from the primary level to the secondary and tertiary levels.

There are no stationed doctors in Health Centres (HCs) and clinics; therefore, clinics refer patients directly to district hospitals rather than to HCs. District hospitals refer patients to regional hospitals, which in turn refer their patients to intermediate hospitals. There are only three intermediate referral hospitals countrywide, namely, Katutura, Oshakati, and Rundu. The Katutura Intermediate Referral Hospital (KIRH) also acts as a national referral hospital, as both the Oshakati and Rundu hospitals refer patients to KIRH. The KIRH has specialist wards with specialist positions catered for at its establishments as well as providing a range of specialist medical services. However, if no specialized wards are found at Katutura State Hospital, all cases requiring specialized treatment will be referred to the Windhoek Central Hospital, which is the national hospital.

\section{Methodology}

The study, which served as a basis for this article, used a mixed-methods research design. A mixed-methods approach involves collecting, analyzing, and mixing qualitative and quantitative data in a single study. It is premised on the idea that the use of quantitative and qualitative approaches in combination provides a better understanding of research problems than either approach alone [7].

Questionnaires were administered to 140 practicing medical doctors at Katutura and Windhoek Central state hospitals, while fifteen doctors were interviewed telephonically, using a semi-structured interview guide. Quantitative data were analyzed using SPSS (Version 25 qualitative data were analyzed using content analysis.

\section{Findings and Discussion}

This study is the first fact-finding study on information needs and informationseeking behavior of practicing medical doctors at Katutura and Windhoek Central hospitals in Namibia. Data were gathered through a questionnaire and telephonic interviews. The two data-gathering techniques were used sequentially. The interviews were a follow up to the findings of the questionnaire survey.

\subsection{Information Needs of Medical Doctors}

The questionnaire provided an overview of issues surrounding the information needs and information-seeking behavior of practicing medical doctors, while the interviews gave in-depth views of the participants around the same issues arising from the questionnaire.

Respondents were asked about the information needs that applied to their medical practice. Table 1 summarizes the information needs of medical doctors 
using a list constructed based on the literature review. In this study, respondents indicated that they needed information for all the different reasons on the list, albeit in various measures.

The respondents indicated that they needed information for all the different reasons that the researcher had listed, albeit in various measures (Table 1).

Although medical doctors need information for all the reasons stated above, the majority indicated that they needed information for improving clinical decision-making (83.1\%), keeping up-to-date (83.1\%), improving their knowledge (83.1\%) and continuing education (81.7\%). The results of this study concur with Wilson's 1996 model of information seeking, which states that information needs can be physiological, emotional or cognitive.

\subsubsection{Improving Clinical Decision-Making}

As evident in Table 1, seeking information to improve clinical decision-making

Table 1. Information needs of medical doctors.

\begin{tabular}{|c|c|c|c|c|c|c|c|}
\hline & & \multicolumn{2}{|c|}{ Male } & \multicolumn{2}{|c|}{ Female } & \multicolumn{2}{|c|}{ Total } \\
\hline & & Count & $\%$ & Count & $\%$ & Count & $\%$ \\
\hline \multirow{2}{*}{$\begin{array}{l}\text { Improving your clinical } \\
\text { decision-making }\end{array}$} & No & 8 & $11.3 \%$ & 4 & $5.6 \%$ & 12 & $16.9 \%$ \\
\hline & Yes & 23 & $32.4 \%$ & 36 & $50.7 \%$ & 59 & $83.1 \%$ \\
\hline \multirow{2}{*}{ Keeping up-to-date } & No & 8 & $11.3 \%$ & 4 & $5.6 \%$ & 12 & $16.9 \%$ \\
\hline & Yes & 23 & $32.4 \%$ & 36 & $50.7 \%$ & 59 & $83.1 \%$ \\
\hline \multirow{2}{*}{$\begin{array}{l}\text { Improving your } \\
\text { knowledge }\end{array}$} & No & 6 & $8.5 \%$ & 6 & $8.5 \%$ & 12 & $16.9 \%$ \\
\hline & Yes & 25 & $35.2 \%$ & 34 & $47.9 \%$ & 59 & $83.1 \%$ \\
\hline \multirow{2}{*}{ Continuing education } & No & 8 & $11.3 \%$ & 5 & $7.0 \%$ & 13 & $18.3 \%$ \\
\hline & Yes & 23 & $32.4 \%$ & 35 & $49.3 \%$ & 58 & $81.7 \%$ \\
\hline \multirow{2}{*}{$\begin{array}{l}\text { Sharing knowledge with } \\
\text { your colleagues }\end{array}$} & No & 9 & $12.7 \%$ & 9 & $12.7 \%$ & 18 & $25.4 \%$ \\
\hline & Yes & 22 & $31.0 \%$ & 31 & $43.7 \%$ & 53 & $74.6 \%$ \\
\hline \multirow{2}{*}{$\begin{array}{l}\text { Answering colleagues' } \\
\text { questions }\end{array}$} & No & 10 & $14.1 \%$ & 14 & $19.7 \%$ & 24 & $33.8 \%$ \\
\hline & Yes & 21 & $29.6 \%$ & 26 & $36.6 \%$ & 47 & $66.2 \%$ \\
\hline \multirow{2}{*}{$\begin{array}{c}\text { Answering patient's } \\
\text { questions }\end{array}$} & No & 11 & $15.5 \%$ & 9 & $12.7 \%$ & 20 & $28.2 \%$ \\
\hline & Yes & 20 & $28.2 \%$ & 31 & $43.7 \%$ & 51 & $71.8 \%$ \\
\hline \multirow{2}{*}{$\begin{array}{l}\text { Writing reports/research } \\
\text { paper not for publication) }\end{array}$} & No & 18 & $25.4 \%$ & 24 & $33.8 \%$ & 42 & $59.2 \%$ \\
\hline & Yes & 13 & $18.3 \%$ & 16 & $22.5 \%$ & 29 & $40.8 \%$ \\
\hline \multirow{2}{*}{$\begin{array}{l}\text { Writing reports/research } \\
\text { paper (for publication) }\end{array}$} & No & 19 & $26.8 \%$ & 29 & $40.8 \%$ & 48 & $67.6 \%$ \\
\hline & Yes & 12 & $16.9 \%$ & 11 & $15.5 \%$ & 23 & $32.4 \%$ \\
\hline \multirow{2}{*}{$\begin{array}{c}\text { Teaching staff/students/ } \\
\text { colleagues (case presentations) }\end{array}$} & No & 9 & $12.7 \%$ & 8 & $11.3 \%$ & 17 & $23.9 \%$ \\
\hline & Yes & 22 & $31.0 \%$ & 32 & $45.1 \%$ & 54 & $76.1 \%$ \\
\hline
\end{tabular}


was a major factor in the survey. This was confirmed by most interviewees who said that improving their knowledge helped them in making decisions regarding what treatment to administer to their patients.

Similarly, many studies and literature reviews on information needs and information-seeking behavior of medical professionals have revealed that they need information to help inform patient diagnosis or treatment [8]-[15]. Bryant [16] concurs that the clinical care of patients is the primary reason for seeking information. It should be noted that in this current study, clinical decision-making encompasses clinical care. This finding is also echoed by Dorsch's review of literature on the information needs of rural health professionals, in which patient care emerged as the primary reason for seeking information [17]. Contrarily though, Strother, Lancaster, and Gardiner's study revealed that the majority of dentists (89\%) sought information primarily to keep up with new developments [18]. Patient care was ranked second (85\%) in Strother et al.'s study. This is probably because dentists use tools that continually change frequently and they need to keep up-to-date with the new developments, while other medical doctors deal with a range of complex scenarios and may need information primarily to make clinical decisions. These differences confirm Wilson's 1996 model, which states that the rise of a particular information need is influenced by the context. The context includes the role that the person plays [19].

The above discussion shows that the need for information to help with decision-making is not peculiar to the Namibian or African medical doctors, as literature has confirmed it to be a global need.

\subsubsection{Keeping Up-to-Date}

Most of the interviewees indicated that the nature of their profession required them to keep up-to-date with what is going on in the medical field. One mentioned that there are new researches conducted every day; hence the need for one to keep up-to-date with what is going on.

These results are similar to the findings of Nwezeh et al.'s study [20], which revealed that all (100\%) doctors need information on new developments in their areas of specialty. Another survey found that keeping up with current information to improve knowledge was the most frequently mentioned information need by participants [21].

The interviewees provided more details on why keeping up-to-date with current health information was one of the most important information needs for medical doctors. The interviewees mentioned that it helps them to make the best clinical decisions and that good medical practice can only be achieved through keeping up-to-date with current information.

According to the Namibian Medical and Dental Professions Act 1993, No. 2851 , it is misconduct for a medical practitioner to participate in a discussion of health issues without possessing the necessary knowledge [22].

\subsubsection{Improving Knowledge/Continuing Education}

In this study, a high percentage $(83.1 \%)$ of the questionnaire respondents indi- 
cated that they needed information to improve their knowledge, while $81.7 \%$ ticked "continuing education". Most interviewees concurred that improving their knowledge would help with making decisions as to what treatment to prescribe to their patients.

Several studies on different user groups [8] [11] [14] [23]-[31] have confirmed that improving knowledge is one of the main reasons why information users seek information. Arraid's study found that the main contexts that give rise to doctors' information needs are education and clinical practice [8]. In Arraid's study, ambiguity, uncertainty, rare diseases, and the multiplicity of options were the motivations for information seeking. Norbet and Lwoga's study on the information-seeking behavior of physicians in Tanzania also found that physicians needed information to enhance their knowledge on a daily basis for patient care [24]. Younger's review on Internet-based information-seeking behavior amongst doctors and nurses showed that their reasons for searching for information online are primarily patient care and continuing professional development [32].

It can therefore be concluded from the discussion above that medical doctors need information primarily to enhance their clinical decision-making, to keep up-to-date, and to improve their professional knowledge (continue education). Wilson asserts that there must be a motivating factor for an information need to arise, which, in this case, is the need to enhance clinical decision-making, to keep up-to-date, and to improve professional knowledge [33]. AI-Dousari concurs that these three needs are essential in clinical decision-making [11]. The satisfaction of all these information needs leads to good medical practice [34]. Wilson asserts that information needs are caused by primary needs, which are, in this case, the need to make clinical decisions, keep up-to-date, and improving professional knowledge [33]. These three core needs are therefore closely related in ensuring good clinical practice, as illustrated in Figure 1.

The results of this study, as well as reviewed literature, have confirmed that it is a good medical practice for doctors to seek information for clinical decision-making, keeping up-to-date, and improving knowledge.

\subsection{Information-Seeking Behaviour and Information Sources Used by Practising Medical Doctors at Katutura and Windhoek Central State Hospitals}

Wilson points out that, depending on personal and contextual factors, information needs may translate into information-seeking behavior as individuals respond to those needs [36]. Information-seeking behavior includes the purposive seeking of information in relation to one's problems, tasks or goals. However, sometimes people seek information simply out of a desire to acquire more knowledge. Information-seeking behavior includes unintentional as well as purposive behaviors that may not necessarily involve seeking but actively avoiding information. According to Wilson, the risk or reward involved in information seeking may lead to active or passive information-seeking behavior [33]. 


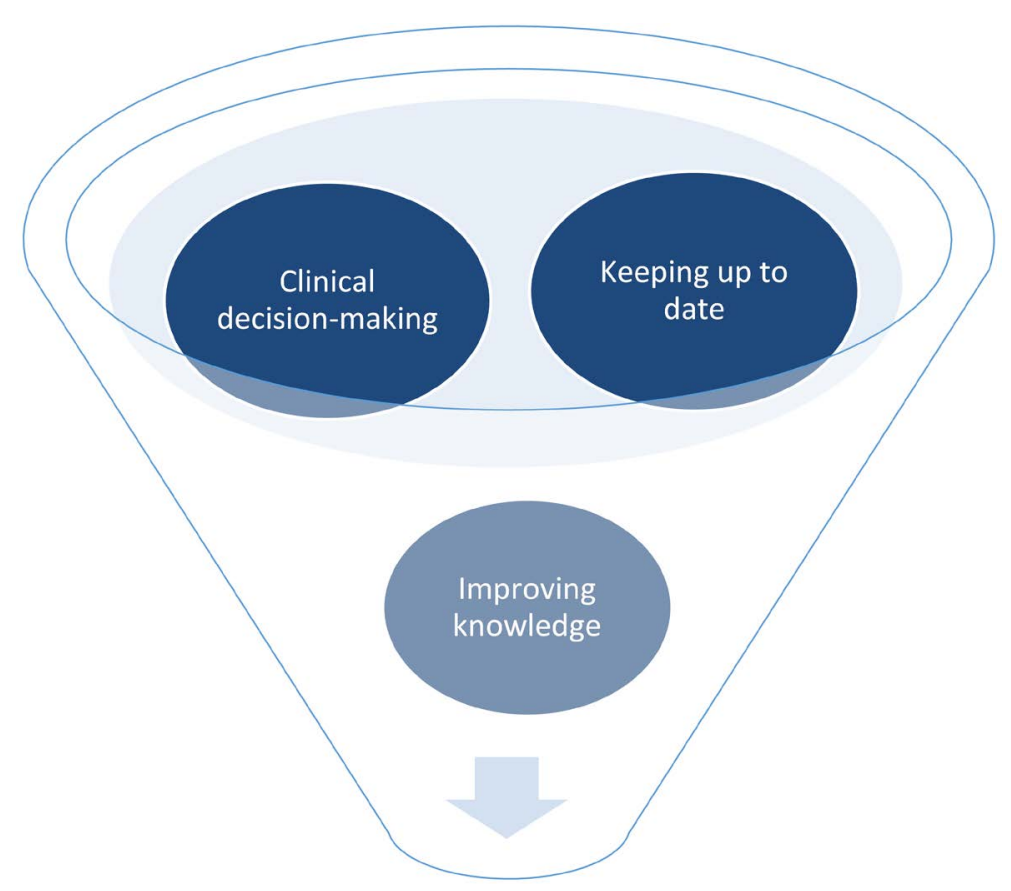

Figure 1. Components of good medical practice by doctors (Source: [35], adapted from [11]).

The sources and resources of information may, inter alia, include hospital libraries, departmental collections, office telephones, mobile phones (provided by the hospital), Internet, online databases, personal collection, annual reports, statistical reports and meetings. The availability and accessibility of these information sources play a very significant role as far as the information-seeking behavior of medical doctors is concerned.

The study has revealed that medical doctors use different information sources to do their work. The results of this study show that doctors use office telephones (83\%), Internet (90.1\%), personal collection (78.9\%), and meetings $(85.9 \%)$ as sources of information. The basis for using these information sources is their availability, accessibility, timeliness, and trustworthiness. Only a few of them use hospital libraries, departmental collections, mobile phones, online databases, annual reports, and statistics because they are not available to everyone and, where they are available, they are not up-to-date or are not accessible. This is in line with Wilson's 1996 model of information seeking, which points out that the characteristics of an information source can be a motivating factor or hindrance to information seeking [1]. The study has also revealed that the information-seeking behavior and information sources used by medical doctors vary based on the clinical context in which the doctor is operating; namely, wards, outpatients, and emergency (or casualty). In the wards, doctors seem to be a bit more relaxed as they are able to refer to information resources more, compared to the outpatient department. However, patient data remains the most used information source compared to information resources (such as hospital libraries, medical databases, Internet) and doctors' personal knowledge and experience. 
The majority of respondents who visited the library indicated that they do so mainly to access books. This could be because books are expensive; thus, visiting a library to use books is understandable. Another possible reason for visiting libraries to use books is that books are not affected when there is no electricity, unlike the Internet. Even though the Internet is available at the hospitals, it is not easily accessible, as doctors are not provided with mobile phones to use at the hospitals. The availability of libraries and the Internet does not change the information needs as the needs are necessitated by the context or the role that the doctor plays.

The study revealed that the majority of the medical doctors at Katutura and Windhoek Central hospitals did not visit libraries, as Windhoek Central Hospital did not have a library and the one at Katutura Hospital was not satisfactory. The medical doctors who visited the Katutura Hospital library did so to look for books. The study also revealed that when the participating medical doctors needed to obtain information from the library, they would mostly ask librarians or search the catalogue. Although the results showed a lack of ICT resources in the two hospitals, the doctors who were interviewed indicated a heavy reliance on ICT resources for clinical information. Most of them indicated that they used the Internet at their homes (93\%) and not at the hospital.

The study revealed that those medical doctors who frequently visited the library or used the Internet did so to keep up-to-date, continue education, and improve. The purpose concurs with Wilson's fourth phase of information search, which states that even when someone is knowledgeable about a specific subject, they still need to continuously search for information to keep up-to-date. However, a high number of participants (23.9\%) indicated that they "never" used the library for personal use as there was no library at Windhoek Central Hospital and the one at Katutura Hospital was poorly equipped.

\subsection{Factors Affecting Practising Medical Doctors at the Two Hospitals in Accessing and Acquiring Information}

Information needs may arise in contexts that may affect doctors' informationseeking behavior. Wilson's 1996 model of information seeking notes that intervening variables, such as environment, and information source characteristics have an effect on the information-seeking behavior of the information seeker [1]. Factors are situations, conditions, or contexts that may affect the way one does his or her work. As information needs arise, there are situations that may affect medical doctors in their endeavour to search for the needed information.

Although this current study revealed that doctors' communication with patients was one of the most common forms of interpersonal communication that enabled them to obtain patient data, most of the interviewees expressed dissatisfaction with their communication with patients for various reasons, including language issues. Another factor is that of medical terminology. Patients do not understand medical terms, which is possibly why doctors recommended or suggested health education for patients as a way of improving communication with 
patients. The results of the study indicate that some hospitals do not have libraries and where libraries exist, they may not be well equipped, thus negatively affecting the information-seeking behavior of doctors. The study has also revealed another worrisome factor; that of missing patients' files, which results in doctors attending to patients without the necessary documents.

Lastly, the study has revealed that doctors (31\%), do not have enough time to talk to patients, as there are so many of them to be attended to. This, in a way, affects not only the quality of their consultation but their information-seeking behavior as well. These findings concur with Wilson's 1996 model of information seeking, which states that factors related to one's social role, environment, and information source characteristics might motivate or hinder information seeking [1].

\subsection{Models for Improving Information Provision of Medical Doctors}

Following Wilson's 1996 model of information seeking [1], I propose three information models for improving information provision for medical doctors. It should be noted that although the models look somewhat similar to some models [11], the models in this study are based primarily on the findings of this particular study.

The proposed conceptual models take into consideration the information needs of practicing medical doctors, the information-seeking behavior and information sources used by practicing medical doctors, the factors affecting medical doctors' information seeking, and the suggestions by the medical doctors. The barriers to effective information-seeking according to Wilson may be psychological, demographic, role-related, interpersonal, environmental or information source characteristics. The first model shows that contextual and information source factors surrounding medical doctors interdependently affect their clinical decision making. The second model describes medical doctors' information-seeking in three clinical contexts, namely, outpatient department, wards, and casualty/emergency department. The third model was developed to illustrate an overall picture of the information needs and information-seeking behavior of practicing medical doctors at Katutura and Windhoek Central hospitals.

\subsubsection{Doctors' Decision-Making Model}

The results of this study have shown that the context in which the doctor operates and the information sources and resources available affect their clinical decision-making.

Doctors' clinical decision-making is influenced by a number of factors (Figure 2). First, the context within which the doctor is operating will determine how he or she makes decisions. These contexts include socio-cultural context, organizational context and clinical context. Socio-cultural context involves factors such as language, cultural beliefs based on patient's age and gender, relationships of a patient with relative who brings the patient and the ability of the patient to 
communicate. Organizational context involves such factors as nature of hospital, facilities, communication systems in the hospital, hospital policies, and the general organizational environment. Clinical context refers to the clinical department the doctor is operating in, i.e. outpatient department, wards, or emergency department. It should be noted from the model that the clinical context operates within the organizational context, which in turn operates within the socio-cultural context. Another factor that influences doctors' decision-making is the information sources and resources available. These include patient data, information resources, and the doctors' personal knowledge and experience. The context and the information sources and resources available work interdependently to influence the doctors' clinical decision-making.

\subsubsection{Clinical Context Information Source Model}

The results of this study have shown that the use of information sources and resources depends on the clinical context that the doctor is operating within. The model below gives a picture of the degree of use of information sources and resources in the three clinical contexts based on the findings.

Although all three types of information sources and resources are critical in all three clinical contexts, their degree of use varies as shown in Figure 3. In the Outpatients department, doctors refer to patients' data more than they refer to their personal knowledge and experience or information resources. Information resources are used less. However, the doctor's personal knowledge and experience are used more than information resources. The Wards seem to be a little bit more relaxed for doctors, as they are able to refer to information resources a bit more. However, patient data remains the most used information source compared to information resources and doctors' personal knowledge and experience. The Emergency department is quite different because of its urgent nature. Here, the doctor relies mostly on his or her personal knowledge and experience, although patient data plays a critical role in the clinical decision-making of an emergency doctor. The use of information resources in the emergency

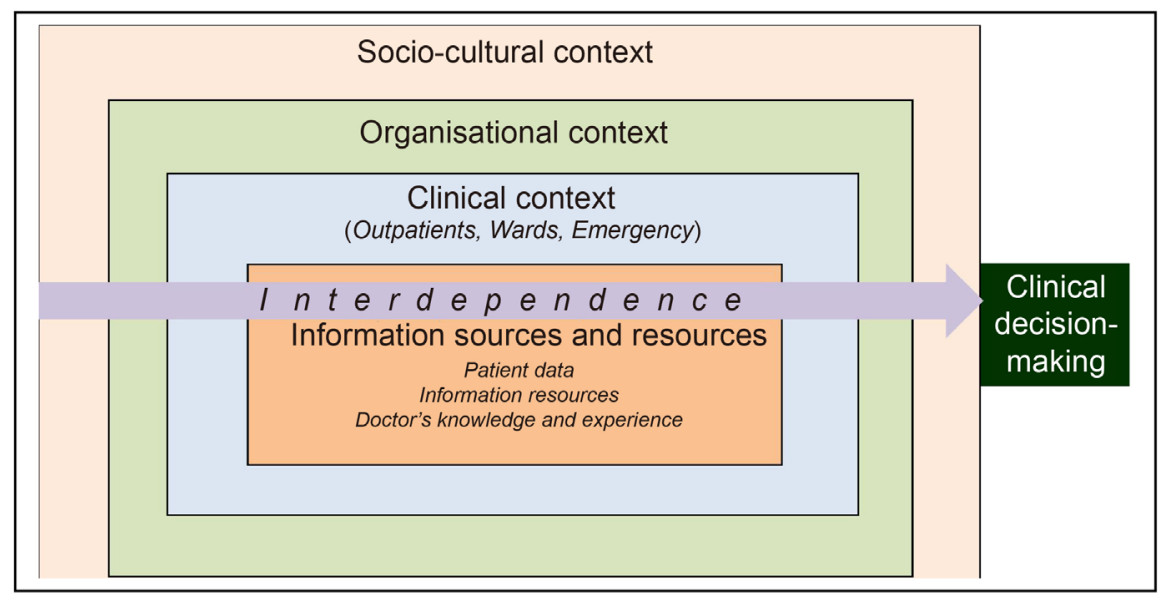

Figure 2. Doctors' decision-making model (Source: [35]). 


\section{OUTPATIENTS}

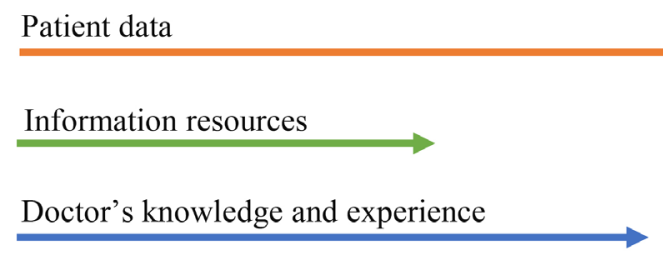

\section{WARDS}

\section{Patient data}

Information resources

Doctor's knowledge and experience

\section{EMERGENCY}

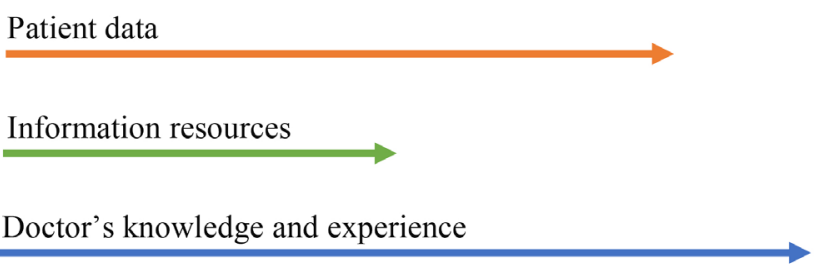

Figure 3. Clinical context information source model (Source: [35]).

room is much less compared to the Outpatients and the Wards.

\subsubsection{Model of Information Needs and Information-Seeking Behavior of Medical Doctors}

The conceptual model of information needs and information-seeking behavior of medical doctors presented in Figure 4 shows that the information-seeking behavior of practicing medical doctors is influenced by their duties as medical doctors and the information needs that arise therefrom. Doctors seek information from the information sources available to them. In this study, patient data, information resources and the doctors' personal knowledge and experience were found to be the main information sources used by medical doctors for clinical decision-making. However, information sources should not only be available, but they should also be easily accessible to the doctors.

Contextual factors also have an impact on doctor's information needs and information-seeking behavior and in turn clinical decision-making. Clinical decision-making is therefore influenced by whether the information needs of a medical doctor are met, and by the doctor's information-seeking behavior, which is influenced by the availability and accessibility of information sources. 


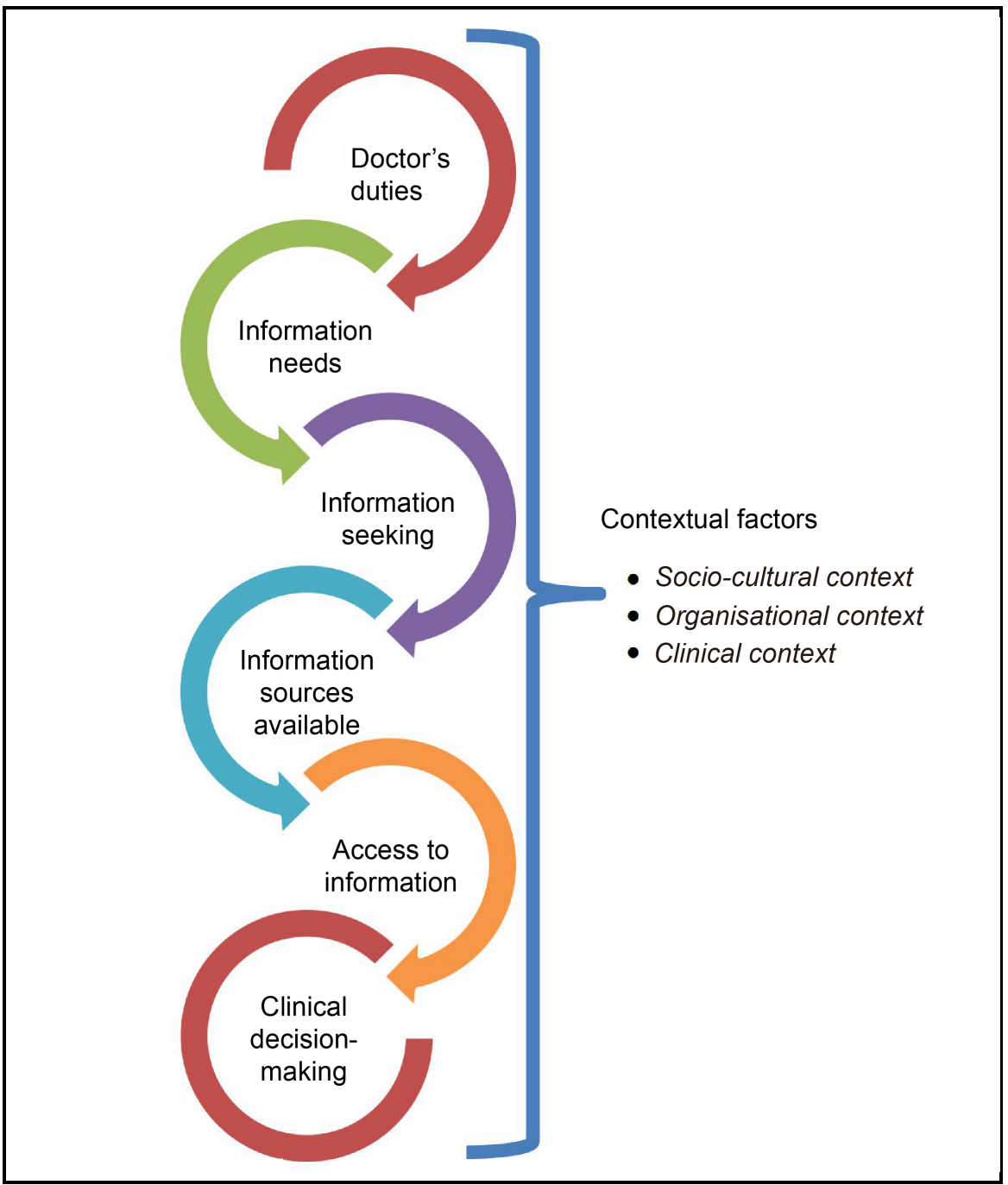

Figure 4. Model of information needs and information-seeking behaviour of medical doctors (source: [35]).

\section{Conclusions}

The study revealed that medical doctors need information for improving clinical decision-making, keeping up to date, improving knowledge, and continuing education. Personal collections and the Internet are the preferred information sources and resources compared to libraries because they are more easily accessible and can be used at any place and whenever necessary. The study also revealed that language problems in communicating with patients/patient's relatives, lack of patients' understanding of medical terms, unavailability of libraries and missing patients' files are some of the major factors that affect the information-seeking behavior of doctors. Medical doctors indicated that they were satisfied with their communication with colleagues and patients. However, their communication with colleagues is affected by the lack of information technology such as video conferencing and mobile phones. The study concluded that there is no relationship between language barriers and nationality. Doctors stressed the need to im- 
prove current health information provision in hospitals through providing health education to patients, setting an environment where doctors can communicate with other local and international hospitals; providing functional medical hospital libraries, training and providing qualified library staff, and training doctors on the use of the Internet and ICTs.

Three models (doctors' decision-making model, clinical context information source model and model of information needs and information-seeking behavior of medical doctors) of medical doctors' information seeking were proposed. The researcher hopes that these models will enhance the information service provision of practicing medical doctors at Katutura and Windhoek central state hospitals and beyond.

\section{Acknowledgment}

I thank Dr Florence Matsveru (my wife) for editing my work.

\section{Conflicts of Interest}

The author declares no conflicts of interest.

\section{References}

[1] Wilson, T.D. and Walsh, C. (1996) Information Behaviour: An Interdisciplinary Perspective. University of Sheffield, Department of Information Studies, Sheffield. https://www.academia.edu/3086444/Information behaviour an interdisciplinary p erspective

[2] Ronald, D. and Wicks, D.A. (2009) A Conversational Model for Qualitative Research: A Case Study of Clergy and Religious Knowledge. Australian Academic \& Research Libraries, 40, 252-265. https://doi.org/10.1080/00048623.2009.10721416

[3] Khudair, A.A. and Cooke, L. (2008) Healthcare Personnel's Use of E-Information Sources in Riyadh Governmental Hospitals. Journal of Librarianship and Information Science, 40, 207-217. https://doi.org/10.1177\%2F0961000608092555

[4] Jacko, J.A., Sears, A. and Sorensen, S.J. (2001) Framework for Usability: Healthcare Professionals and the Internet. Ergonomics, 44, 989-1007. https://doi.org/10.1080/00140130110069202

[5] Khalid, H. (2000) The Use of Technology for House-Keeping and Bibliographic Searching Activities in University Libraries of Saudi Arabia: the Need for Acceleration. Library Review, 49, 179-185. https://doi.org/10.1108/00242530010325472

[6] Watts, C. and Ibegbulam, I. (2006) Access to Electronic Healthcare Electronic Information Resources in Developing Countries: Experiences for the Medical Library, College of Medicine, University of Nigeria. IFLA Journal, 32, 54-61. https://doi.org/10.1177\%2F0340035206063903

[7] Creswell, J.W. (2003) Research Design: Qualitative, Quantitative, and Mixed Methods Approaches. 2nd Edition, Sage, London.

[8] Arraid, A.S.K. (2011) Information Needs and Information Seeking Behaviour of Libyan Doctors Working in Libyan Hospitals. PhD Thesis, Loughborough University, Loughborough.

[9] Kapiriri, L. and Bondy, S.J. (2006) Health Practitioners' and Health Planners' Information Needs and Seeking Behaviour for Decision Making in Uganda. Interna- 
tional Journal of Medical Informatics, 75, 714-721.

https://doi.org/10.1016/j.ijmedinf.2005.10.003

[10] Callen, J.L., Buyankhishiq, B. and Mclntosh, J. (2008) Clinical Information Sources Used by Hospital Doctors in Mongolia. International Journal of Medical Informatics, 77, 249-255. https://doi.org/10.1016/j.ijmedinf.2007.06.003

[11] AI-Dousari, E. (2009) Information Needs and Information Seeking Behaviour of Doctors in Kuwait Government Hospitals: An Exploratory Study. Doctoral Thesis, Loughborough University, Loughborough.

[12] Clarke, M.A., Belden, J.L., Koopman, R.J., Steege, L.M., Moore, J.L., Canfield, S.M. and Kim, M.S. (2013) Information Needs and Information-Seeking Behaviour Analysis of Primary Care Physicians and Nurses: A Literature Review. Health Information \& Libraries Journal, 30, 178-190. https://doi.org/10.1111/hir.12036

[13] Formoso, G., Rizzini, P., Bassi, M., Bonfanti, P. Rizzardini, G., Campomori, A. and Mosconi, P. (2016) Knowledge Transfer: What Drug Information Would Specialist Doctors Need to Support Their Clinical Practice? Results of a Survey and of Three Focus Groups in Italy. BMC Medical Informatics and Decision Making, 16, Article No. 115. https://doi.org/10.1186/s12911-016-0355-7

[14] Brennan, N., Edwards, S., Kelly, N., Miller, A., Harrower, L. and Mattick, K. (2014) Qualified Doctor and Medical Students' Use of Resources for Accessing Information: What Is Used and Why? Health Information \& Libraries Journal, 31, 204-214. https://doi.org/10.1111/hir.12072

[15] Lee, P.J. (2013) The Information Needs of Clinicians: A Study of the Doctors. Nova Scotia Clinical Library. Journal of the Canadian Health Libraries Association/Journal De I Association Des bibliothèques De La Santé Du Canada, 34, 159-163. https://doi.org/10.5596/c13-058

[16] Bryant, S.L. (2004) The Information Needs and Information Seeking Behaviour of Family Doctors. Health Information and Libraries Journal, 21, 84-93. https://doi.org/10.1111/j.1471-1842.2004.00490.x

[17] Dorsch, J.L. (2000) Information Needs of Rural Health Professionals: A Review of the Literature. Bulletin of the Medical Library Association, 88, 346-354.

[18] Strother, E.A., Lancaster, D.M. and Gardiner, J. (1986) Information Needs of Practising Dentists. Bulletin of the Medical Library Association, 74, 227-230.

[19] Case, D.O. (2006) Looking for Information: A Survey of Research on Information Seeking, Needs, and Behavior. 2nd Edition, Emerald Group Publishing, Bingley.

[20] Nwezeh, C.M.T., Shabi, O.M. and Shabi, I.N. (2011) Information-Seeking Behavior of Doctors at the Obafemi Awolowo University Teaching Hospitals Complex, Ile Ife, Osun State, Nigeria. Journal of Hospital Librarianship, 11, 126-139. https://doi.org/10.1080/15323269.2011.558369

[21] Ocheibi, J.A. and Buba, A., (2003) Information Needs and Information Gathering Behaviour of Medical Doctors in Maiduguri, Nigeria. Journal of Educational Media and Library Sciences, 40, 417-427.

[22] Ministry of Health and Social Services (2002) Rules Relating to Improper Conduct or Misconduct by a Medical Practitioner: Medical and Dental Professions Act, 1993. Government Notice No. 197.

[23] Nel, M. and Fourie, I. (2010) An Exploratory Study of the Information Behaviour of Veterinary Practitioners in South Africa. Mousaion, 28, 107-133.

[24] Norbet, G.L. and Lwoga, E.T. (2012) Information Seeking Behaviour of Physicians in Tanzania. Information Development, 29, 172-182. 
https://doi.org/10.1177\%2F0266666912450449

[25] Andualem, M., Kebede, G. and Kumie, A. (2013) Information Needs and Seeking Behaviour among Health Professionals Working at Public Hospital and Health Centres in Bahir Dar, Ethiopia. BioMed Central Health Service Research, 13, Article No. 534. https://doi.org/10.1186/1472-6963-13-534

[26] Mabhiza, C. (2016) An Investigation of the Information Seeking Behaviours of Veterinary Scientists in UNAM. Unpublished Thesis, University of Namibia, Windhoek.

[27] Mabhiza, C., Shatona, M. and Hamutumwa, N. (2012) Information Seeking Behaviours of the Faculty of Economics and Management Sciences, University of Namibia. In: Ilvonen, M., Helminen, P., Ndinoshiho, J. and Sisatto, O., Eds., Empowering People: Collaboration between Finnish and Namibian University Libraries, Tampere University Press, Tampere, 79-99.

[28] Chikonzo, A.C. and Aina, LO. (2001) The Information Environment of Veterinary Researchers at the University of Zimbabwe. International Information and Library Review, 33, 97-111. https://doi.org/10.1080/10572317.2001.10762541

[29] Vali, K.S. and Esmail, S.M. (2014) A Study of Information Needs and Information Seeking Behavior of Faculty in Government Medical Colleges of Karnataka. International Journal of Library Science and Research, 4, 51-56.

[30] Prakasan, P.M. (2013) Information Needs and Use of Healthcare Professionals: International Perspective. Journal of Library \& Information Technology, 33, 465-473.

[31] Singh, R.K. (2012) Information Seeking Behaviour of Medical Practitioners: A Case Study. International Journal of Information Research, 2, 28-43.

[32] Younger, P. (2010) Internet Based Information Seeking Behaviour amongst Doctors and Nurses: A Short Review of the Literature. Health Information and Libraries Journal, 27, 2-10. https://doi.org/10.1111/j.1471-1842.2010.00883.x

[33] Wilson, T.D. (1999) Models in Information Behaviour Research. Journal of Documentation, 55, 249-270. https://doi.org/10.1108/EUM0000000007145

[34] González-González, A.I., Dawes, M., Sánchez-Mateos, J., Riesgo-Fuertes, R., Escortell-Mayor, E., Sanz-Cuesta, T. and Hernández-Fernández, T. (2007) Information Needs and Information-Seeking Behaviour of Primary Care Physicians. Annals of Family Medicine, 5, 345-352. https://doi.org/10.1370/afm.681

[35] Matsveru, D. (2020) Information Needs and Information-Seeking Behaviour of Practising Medical Doctors at Katutura and Windhoek Central State Hospitals in Namibia, PhD Thesis, University of Fort Hare, Alice.

[36] Wilson, T.D. (2000) Human Information Behaviour. Informing Science, 3, 49-56. https://doi.org/10.28945/576 